\title{
The Introduction of Self Help Group Facilitator in an Alcohol Unit: Preliminary Results
}

\author{
Patrizia Balbinot* and Gianni Testino
}

Alcohological Regional Centre, Unit of Addiction and Hepatology, Polyclinic Hospital, Italy

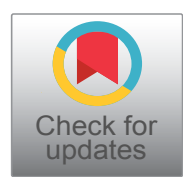

*Corresponding author: Patrizia Balbinot, Centro Alcologico Regionale e SC Patologia delle Dipendenze ed Epatologia ASL3 c/o Padiglione 10 (piano terra), Ospedale Policlinico San Martino, Piazzale R. Benzi 10, 16132 Genova, Italy, Tel: 0039-10-5552769, Fax: 0039-10-5556738

\begin{abstract}
The main outcome of Alcohol Use Disorders (AUDs) treatment is the achievement of abstention.

Pharmacological and psychosocial activities are strictly imbricated, however the results at one year are still unsatisfactory.

To date, the most effective tool for maintaining abstention is attendance at Self-Mutual-Help Groups (SHGs).

Despite that, to date few patients attend Self-Help Groups (SHGs). For this reason we have decided to introduce the Self-Help Group Facilitator (SHGF) to our service.

After the introducing of SHGF, more patients have attended the SHGs. Moreover, there was an overall reduction in alcohol consumption.

It is suggestive to image how a social health operator in collaboration with SHGs can improve clinical progress, at lower cost.
\end{abstract}

\section{Keywords}

Alcohol Use Disorders, Self-Help Group Associations, SelfHelp Groups Facilitator, Caregiver

\section{Introduction}

The main outcome of Alcohol Use Disorders (AUDs) treatment is the achievement of abstention.

Follow-up of untreated or treated patients in non-accredited structures found an average abstention of one year of $21 \%$ [1].

Pharmacological and psychosocial activities are strictly imbricated, however the results at one year are still unsatisfactory. After formal treatment, meta-ana- lyzes find abstinence from 25 to $43 \%$. Percentages that vary in relation to the intensity of the treatment and the length of the follow-up [2-6]. The abstinence rate decreases significantly over time.

It is well known that Self-Mutual-Help Groups (SHGs) are key in promoting long-term sobriety.

Anonymous Alcoholics (AA) in the United States of America have played an important role since 1935. In Europe Vladimir Hudolin has introduced alcoholics in treatment clubs.

In a paper of 1969 Hudolin affirmed: "During the patient's treatment he forms part of the Club of treated alcoholics, which works within the framework of the Institute..... Simultaneously the patient work in local clubs, in which they will become members after their treatment is finished. The final purpose of such work is to aim that the club should become an auto-psychotherapeutic group in which the alcoholic will exert maximum activity for the benefit of his own treatment" [7].

Scientific evidence has shown the effectiveness of the SHGs even if it is not associated with pharmacological and psychotherapeutic treatments. In addition, a lot of studies have proven the long-term efficacy of this tool both in relation to drug therapy and psychotherapy [8-19].

These positive results have also been reported in patients with psychiatric comorbidity [15].

Recently a Cochrane Systematic Review (27 studies containing 10.565 participants; 21 RCTs/quasi-RCTs, 
5 non-randomized, and 1 purely economic study) evidenced that manualized $A A$ interventions are more effective than other established treatments such as cognitive behavioral therapy, for increasing abstinence. Probably the AA frequency allows a better cost-benefit ratio [20].

Despite these results, to date few patients attend self-help groups. In 2018, the Italian Health Minister's Report to Parliament stated that only $4.8 \%$ of patients attend them [21].

In real practice it is very difficult to access patients to groups.

The reasons are many, however the most significant are the following: distrust on the part of patients and healthcare professionals and lack of time to devote to describing self-help groups.

It is good to underline how a constructive relationship with the family or friend of the AUD patient who decides to support the patient (Informal Caregiver - IC) is also crucial. Sometimes this contact is missing. Family members often no longer have resources available [22].

For this reasons, according to the initial activity of Hudolin [7], we favored the establishment of SHGs within our Institute and we have decided to introduce the Self-Help Group Facilitator (SHGF) to our service. This figure can be carried out by a healthcare professional with experience in an alcoholic unit and with a proven knowledge of SHGs.

SHGs activity is as follows: Explore possible barriers, describe the different ones "empathically" associations, break down negative myths, inform about positive aspects and results, give courage and monitor frequency.

In our service the role is played by a socio-health operator. This operator also moderates the groups for IC (ICGs) monthly.

\section{Methods}

In our Addiction Unit, the SHGF was introduced in June 2019. The patients were inserted from January 2020 to June 2019. All AUD patients are affected by compensated Alcohol related Liver Disease (ALD) and have been divided into two groups. The observational study was conducted retrospectively. Group A: 40 patients (12 females and 28 males) immediately after the first medical visit met the SHGF. During the visit (average duration $45^{\prime}-60^{\prime}$ ) the groups (AA and alcoholics in treatment clubs) are described and the advantages discussed. In addition, the SHGF meets the patient's family or friends and asks to participate in the ICGs. These groups discuss possible problems or progress and therapeutic adherence.

Group A was compared with Group B made up of 40 patients ( 15 females, 25 males) traditionally accepted in the same period of time.
Patients in group B were only given the telephone number or email of the associations with general information on the activity carried out.

All patients signed informed consent and consent to scientifically process data anonymously. These consents are kept in the medical records.

AUDs were diagnosed with the Diagnostic and Statistical Manual of Mental Disorders (DSM) $5^{\text {th }}$ Edition Criteria [23].

Monthly drinking variables were derived from the Timeline Follow-Back [24] that provided information of daily number of standard drinks. To define standard drinks, a conversion card was provided. The conversion of recorded standard drinks to grams was performed by a statistical programmer with the following Italian-specific factor: 12 grams. At screening patients reported their daily drinking over the previous month (28 consecutive days). At subsequent visits, they reported drinking since the previous visit [25].

The certainly of abstention is given by the random evaluation of urinary ethylglucuronide.

Greater psychiatric comorbidity is present in overlapping percentages (Group A: 25\%, Group B: 20\%).

All patients underwent psychotherapy.

Being patients with liver disease, they did not undergo adversive/anticraving therapy with hepatotoxic or potentially hepatotoxic drugs. Only a minority part was subjected to acamprosate therapy (15\% in the reference group and $\mathbf{1 7 . 5 \%}$ in the control group).

Follow up was carried out until October 2020 (5-9 months).

The potential outcomes to be calculated are many. At present, the following outcomes have been assessed: Frequency at SHGs, frequency at ICGs and abstention or reduction of alcohol consumption over $50 \%$.

In consideration of the short follow-up period, the cases that achieved complete abstention were added to those with a significant reduction in consumption (> $50 \%)$.

Statistical analysis: Fisher exact test calculator for a 2 $\times 2$ contingency table.

\section{Results}

The results are summarized in Table 1 and Table 2.

The number of patients who had access to the groups is significantly greater in group A $(70 \%$ vs. $10 \%$, $<0.00001)$ as is the number of patients who have had an active and collaborative IC ( $60 \%$ vs. $5 \%,<0.00001)$ (Table 1).

In group $A$ there was an overall reduction in alcohol consumption compared to group B ( $70 \%$ vs. $45 \%$, < 0.0411) (Table 2). 
Table 1: SHGF: Self-Help Group Facilitator, Self-Help Groups Frequency (SHGF Freq), Informal Caregiver Groups Frequency (ICG Freq), Total Abstension (Abs), < 50\% (consumption reduction of over 50\%), Cons (no changes in consumption).

\begin{tabular}{|l|l|l|l|l|l|l|l|l|}
\hline & Cases & SHG Freq & ICG Freq & Abs & $<\mathbf{5 0 \%}$ & Abs $+<\mathbf{5 0} \%$ & Cons & Cons $+<\mathbf{5 0 \%}$ \\
\hline Group A (SHGF) & 40 & $28(a)$ & $24(c)$ & 17 & 11 & $28(e)$ & 12 & 23 \\
\hline Group B No SHGF & 40 & $4(\mathrm{~b})$ & $2(\mathrm{~d})$ & 16 & 2 & $18(\mathrm{f})$ & 22 & 24 \\
\hline
\end{tabular}

a-b: $<0.00001$

c-d: $<0.00001$

e-f: $<0.0411$

Table 2: Self-help mutual groups frequency and/or informal caregiver groups frequency and alcohol consumption abstension or significant consumption unchanged reduction consumption (SHMGs: Self-help mutual groups, ICGs: Informal caregivers groups).

\begin{tabular}{|l|l|l|l|}
\hline & Cases & $\begin{array}{l}\text { abstension or significant } \\
\text { reduction consumption }\end{array}$ & consumption unchanged \\
\hline SHMGs + ICGs frequency & $19 \mathrm{a}$ & $18 / 19(94.7 \%)$ & $1 / 19(5.2 \%)$ \\
\hline SHMGs or ICGs frequency & $18 \mathrm{~b}$ & $12 / 18(66.6 \%)$ & $6 / 18(33.3 \%)$ \\
\hline No frequency & $43 \mathrm{c}$ & $16 / 43(37.2 \%)$ & $27 / 43(62.7 \%)$ \\
\hline
\end{tabular}

a-c: 0.0002

a-b: 0.0422

b-c: 0.0496

In cases where there is a simultaneous attendance at SHMGs and ICGs, the reduction in consumption increases in a highly significant way compared to those who attend only one of the two $(<0.0422)$ or those who do not attend any group $(<0.0002)$ (Table 2$)$.

\section{Conclusions}

It emerges as a figure dedicated to managing the relationship with SHGs can be crucial to increase the number of patients attending SHGs. If a stable collaboration between family (through ICGs) and alcohol unit is added to this aspect, the result can be even better.

Moreover, it can be assumed that with this type of activity there is a favorable cost-benefit ratio.

In the group of patients received by the SHGF there is also a significant reduction in alcohol consumption. Not foreseeing abstention as a final result even in the most difficult patients is incorrect and also the trust of patients and families is betrayed. However, those with a total abstention have also been added those with a significant reduction in consumption, that is, over $50 \%$. The reduction in consumption, in fact, can have a meaning as a bridge to abstention or in some selected clinical and environmental conditions.

In addition, Roereche and Rehm [26] found that reducing 14 to 11 alcoholic beverages per day reduces mortality risk by about 10 times, as does reducing 3 to 0 alcoholic beverages per day.

These results will certainly have to be reconfirmed on a larger patient population, and on a longer follow-up period, however the introduction in the addiction units of the SHGF can help better manage difficult patients and can represent a decisive boundary between service, family and community. This would create a true network between patient, family, associations and ad- diction units with undoubted clinical and socio-health advantages.

It is suggestive to imagine how in the alcohological/ addiction unit a socio-health operator can significantly improve clinical performance, moreover at lower costs.

\section{Discolsure}

The author has no conflicts of interest to disclose.

\section{References}

1. Connor JP, Haber PS, Hall WD (2016) Alcohol use disorders. The Lancet 387: 988-998.

2. Miller WR, Walters ST, Bennett ME (2001) How effective is alcoholism treatment in the United States? J Stud Alcohol 62: $211-220$

3. Monahan SC, Finney JW (1996) Explaining abstinence rates following treatment for alcohol abuse: A quatitative synthesis of patient research design and treatment effects. Addiction 91: 787-805.

4. Berglund M, Thelander S, Jonsson E (2003) Treating alcohol and drug abuse. An evidence based review. Weinheim: Wiley-VCH.

5. Bottlender M, Kohler J, Soyca M (2006) Effektivitat psychosozialer. Behandlungsmethoden zur medizinischen rehabilitation alkoholabhangiger patienten. Fortsche Neurol Psychiatrie 74: 19-31.

6. Soyka M, Kranzler HR, Berglund M, Gorelick D, Hesselbrock V, et al. (2009) The WFSBP Task Force on Treatment Guidelines for Substance Use Disorders,. World Federation of Societies of Biological Psychiatry (WFSBP) Guidelines for Biological Treatment for Substance Use and Related Disorders, Part 1: Alcoholism. The World Journal of Biological Psychiatry 9: 6-23.

7. Hudolin V (1969) Alcoholism in Croatia. Int J Soc Psychiatry 15: 85-91.

8. Kelly JF (2003) Self-help for substance-use disorders: history, effectiveness, knowledge gaps, and research oppurtinities. Clin Psychol Rev 23: 639-663. 
9. Emrik CD, Tonigan JS, Montgomery H, Laura L (1993) Alcoholic Anonymous: what is currently known? In: McCrady BS, Miller WR, Research on Alcoholics Anonymous: Opportunities and alternatives. Piscataway NJ: Rutgers Center on Alcohol Studies, 41-76.

10. Kelly JF, Yeterian JD (2011) The role of mutual-help groups in extending the framework of treatment. Alcohol Res Health 33: 350-355.

11. Ferri M, Amato L, Davoli M (2006) Alcoholic Anonymous and other 12-step programmes for alcohol dependence. Cochrane Database Syst Rev 19: CD005032.

12. Moos RH, Moos BS (2006) Partecipation in treatment and Alcoholics Anonymous: A 16-year follow-up of initially untreated individuals. J Clin Psychol 62: 735-750.

13. Timko C, Moos RH, Finney JW, Lesar MD (2000) Longterm outcomes of alcohol use disorders: Comparing untreated individuals with those in Alcoholics Anonymous and formal treatment. J Stud Alcohol 6: 529-540.

14. Karrier-Jaffe K, Klinger JL, Witbrodt J, Kaskutas LA (2018) Effects of treatment type on alcohol consumption partially mediated by Alcoholics Anonymous attendance. Subst Use Misuse 53: 596-605.

15. Tonigan JS, Toscova R, Miller WR (1996) Meta-analysis of the literature on Alcoholics Anonymous: Sample and study characteristics moderate findings. J Stud Alcohol 57: 65-72.

16. Forcehimes AA, Tonigan JS (2008) Self efficacy as a factor in abstinence from alcohol/other drug abuse: A meta-analysis. Alcohol treat Q 26: 480-489.

17. Humphreys K, Blodgett JC, Wagner TH (2014) Estimating the efficacy of alcoholics anonymous without self-selection bias: An instrumental variables re-analysis of randomized clinical trials. Alcohol Clin Exp Res 38: 2688-2694.

18. Longabaugh R, Donovan DM, Karno MP, McCrady BS, Morgenstern J, et al. (2005) Active ingredients: How and and why evidence-based alcohol behavioral treatment interventions work. Alcohol Clin Exp Res 29: 235-247.

19. Kownachi RJ, Shadish WR (1999) Does Alcoholics Anonymous work? The results from a meta-analysis of controlled experiments. Subst Use Misuse 34: 1897-1916.

20. Kelly JF, Humphreys K, Ferri M (2020) Alcoholics Anonymous and other 12-step programs for alcohol use disorder. Cochrane Database Syst Review 3: CD012880.

21. Minister of Health. Directorate-General for Health Prevention. Office 6. Report of the Minister of Health to the Parliament on the interventions carried out pursuant to the law 30.03.2001 N. 125 "Framework law on alcohol and alcohol related problems" - Year 2018.

22. Balbinot P, Leone S, Testino G, Caputo F (2020) Hospital readmission of patients with hepatic encephalopaty: Is the introduction of the formal caregiver useful in care management? Dig Liver Dis 52: 358-359.

23. American Psychiatric Association (2013) Diagnostic and statistical manual of mental disorders. ( $5^{\text {th }}$ edn), Arlington. NE.

24. Sobell LC, Sobell MB (1992) Timeline follow-back: A technique for assessing self-reported ethanol consumption. In: Litten RZ, Allen JP, Measuring Alcohol Consumption: psychosocial and biological methods. Totowa, New Jersey: Humana Press, 41-72.

25. Mann K, Bladstrom A, Torup L, Gual A, van den Brink W (2013) Extending the treatment options in alcohol dependence: A randomized controlled study of as-needed nalmefene. Biol Psychiatry 73: 706-713.

26. Roerecke M, Gual A, Rehm J (2013) Reduction of alcohol consumption and subsequent mortality in alcohol use disorders: Systematic review and meta-analyses. J Clin Psychiatry $74: 1181-1189$. 